IJkema, R., Langelaan, M., Steeg, L. van de, Wagner, C. Do patient characteristics influence nursing adherence to a guideline for preventing delirium? Journal of Nursing Scholarship: 2014, 46(3), 147-156

\begin{tabular}{|l|l|}
\hline $\begin{array}{l}\text { Postprint } \\
\text { Version }\end{array}$ & 1.0 \\
\hline Journal website & http://onlinelibrary.wiley.com/doi/10.1111/jnu.12067/abstract \\
\hline Pubmed link & $\underline{\text { http://www.ncbi.nlm.nih.gov/pubmed/24502604 }}$ \\
\hline DOI & $10.1111 /$ jnu.12067
\end{tabular}

This is a NIVEL certified Post Print, more info at http://www.nivel.eu

\title{
Do Patient Characteristics Influence Nursing Adherence to a Guideline for Preventing Delirium?
}

\author{
ROELIE IJKEMA MSC, MAAIKE LANGELAAN PHD,*, LOTTE VAN DE STEEg MSC, CORDUlA \\ WAGNER PHD
}

NIVEL, Netherlands Institute for Health Services Research, Utrecht, the Netherlands and EMGO Institute for Health and Care Research, VU University Medical Center, Amsterdam, the Netherlands

\begin{abstract}
Purpose: The purpose of this study was to examine if the characteristics of patients influence nursing adherence to a quality improvement guideline. This guideline consists of delirium risk screening and preventive care, including the use of the Delirium Observation Screening Scale (DOSS).

Design: A retrospective patient record review study was performed in 18 Dutch hospitals that were implementing a quality improvement project regarding delirium care. The records of patients 70 years of age or older were reviewed over an 11-month period.

Methods: Patient characteristics, as well as the extent of risk screening and the application of the DOSS within the screened and nonscreened groups, were recorded by experienced research nurses. Characteristics were compared between these groups and within the high-risk group using multilevel logistic regression analysis.

Findings: A total of 1,881 patient records were analyzed. In $55 \%$ of the total sample, a risk screening was conducted, of which $44 \%$ were identified as patients with a high risk for delirium. Acute admissions were screened significantly less often. The DOSS was used in $48 \%$ of the patients in the highrisk group, but also in 13\% of the patients without an identified risk and in 15\% of the nonscreened patients. The factors influencing the use of the DOSS in screened and nonscreened patients included age, domestic circumstances, suffering from dementia, and acute admission. In the nonscreened group, comorbidity also showed significance.

Conclusions: Patient characteristics influence nursing in preventive delirium care.
\end{abstract}


IJkema, R., Langelaan, M., Steeg, L. van de, Wagner, C. Do patient characteristics influence nursing adherence to a guideline for preventing delirium? Journal of Nursing Scholarship: 2014, 46(3), 147-156

Clinical Relevance: The findings can help to improve preventive delirium care by nurses.

Delirium is a common condition in hospitalized patients. Occurrence rates vary considerably in the literature from 14\% to 42\% (Siddiqi, House, \& Holmes, 2006). Delirium rates depend on, for example, patient characteristics, the healthcare setting, and the sensitivity of the detection method. The highest rates are found among older hospitalized patients (Inouye, 2006). Previous studies have shown that delirium is associated with negative patient outcomes such as a prolonged hospital stay, adverse effects on functional outcomes, institutionalization, and increased mortality (Eeles et al., 2010; Siddiqi et al., 2006). In addition, it is associated with high medical costs (Inouye et al., 1999; Leslie, Marcantonio, Zhang, Leo-Summers, \& Inouye, 2008). A review by Milisen, Lemiengre, Braes, and Foreman (2005) found that multicomponent preventive intervention strategies were efficacious in reducing the incidence of delirium and had positive effects on duration and severity of delirium and on functional status. No effect of preventive interventions on length of stay or mortality was found (Milisen et al., 2005). Zhang et al. (2013) endorsed that multicomponent interventions were useful in preventing postoperative delirium. To prevent delirium effectively, timely identification is required of patients at risk. Many studies have already focused on the identification of predisposing as well as precipitating factors for delirium. These include age (Elie, Cole, Primeau, \& Bellavance, 1998; Kalisvaart et al., 2006), gender (Elie et al., 1998), functional impairment (Inouye et al., 2007), cognitive functioning (Inouye, Viscoli, Horwitz, Hurst, \& Tinetti, 1993; Kalisvaart et al., 2006; Rahkonen et al., 2001), dementia (Boorsma et al., 2012; Elie et al., 1998; Inouye et al., 2007), high comorbidity (Inouye et al., 2007), severe illness (Inouye et al., 1993), vision impairment (Inouye et al., 1993; Inouye et al., 2007), acute admission (Kalisvaart et al., 2006), biomedical factors (Inouye et al., 1993; Rahkonen et al., 2001), medication (Elie et al., 1998), and the use of physical restraints (Boorsma et al., 2012; Inouye et al., 2007).

Based on existing literature and expert opinion, the Frail Elderly Project (FEP) was developed in the Netherlands. This multicomponent prevention program aims to provide all Dutch hospitals with a program that focuses on prevention of common complications in the elderly, including delirium. The FEP forms part of a national patient safety program that aimed to achieve a $50 \%$ reduction in preventable adverse events in Dutch hospitals (VMS Veiligheidsprogramma,). This program is coordinated and supported by the Dutch Ministry of Health, Welfare and Sport and satisfies the requirements for performance evaluation indicators of the Dutch Health Care Inspectorate. Almost all hospitals in the Netherlands (95\%) are participating in the program. The recommendations of an expert team on delirium care have been bundled together and illustrated in a practical FEP guide, which forms the professional guideline (Dutch Patient Safety Program, 2012). According to the guideline, all participating hospitals are required to systematically screen their hospitalized patients who are 70 years of age and older for delirium risk. Table 1 shows the recommended screening questions. 
IJkema, R., Langelaan, M., Steeg, L. van de, Wagner, C. Do patient characteristics influence nursing adherence to a guideline for preventing delirium? Journal of Nursing Scholarship: 2014, 46(3), 147-156

\section{[TABLE 1]}

One or more questions answered with “yes” indicates a high risk for delirium. Although using the FEP's screening questions is the recommended screening method, hospitals were allowed to choose another screening tool to identify high-risk patients. When a high risk is ascertained, preventive interventions should be applied, varying from interventions aimed at improving cognition and mobility to consultation of experts in the field of delirium, depending on the cause of the high risk. Furthermore, patients who have been identified as high-risk patients should be observed with the Delirium Observation Screening Scale (DOSS) to recognize delirium early. The DOSS is a tool for early detection of delirium by observation during three successive shifts by nurses (Schuurmans, Shortridge-Baggett, \& Duursma, 2003). The scale, which originally had 25 items, is based on the Diagnostic and Statistical Manual of Mental Disorders (4th edition; DSM-IV) criteria for delirium and has shown satisfactory validity and reliability with moderate to good interrater reliability for sum score (Schuurmans, 2001). After further development, the scale was reduced to 13 behavioral items with a specificity of 0.88 and a sensitivity of 0.89 (van Gemert \& Schuurmans, 2007). The final DOSS score varies between 0 and 13, with a cut-off point of 3. A DOSS score of 3 or more indicates that the patient is probably delirious. A review of delirium measurement scales in which 13 instruments were compared showed that the DOSS was recommended for screening older hospitalized patients with a high risk for delirium, whereas the Confusion Assessment Method (CAM) was recommended as a diagnostic tool (Schuurmans, Deschamps, Markham, Shortridge-Baggett, \& Duursma, 2003).

The FEP's guideline is in line with the requirements concerning delirium care of the Dutch Health Care Inspectorate (Dutch Health Care Inspectorate, 2011). However, hospitals' self-reported ratings show insufficient adherence to the guideline as regards screening and the use of the DOSS. On average, 63\% of the hospital departments adhered to screening and 59\% of the high-risk patients were observed with the DOSS or the CAM (Dutch Health Care Inspectorate, 2013). It is important to gain insight into possible factors influencing this in order to better understand nurses' nonadherence and to be able to increase adherence levels to reduce delirium incidence. Therefore, the objective of this study was to examine the association between patient characteristics and nursing adherence to a quality improvement guideline concerning delirium care.

\section{METHODS}

\section{Study Design and Setting}

A retrospective patient record review study was performed in 18 Dutch hospitals that were participating in a stepped wedge trial investigating the effect of the introduction of an e-learning tool on changing delirium care (Van de Steeg, Langelaan, Ijkema, \& Wagner, 2012). All university, tertiary teaching, and general hospitals in the Netherlands were invited $(\mathrm{N}=81)$ to participate in this study, except hospitals already involved in another study evaluating the FEP $(\mathrm{N}=10)$. Specialized hospitals such as eye clinics and cancer hospitals were not eligible for inclusion. Hospitals could be enrolled if they were in the preliminary stage of implementation. Surgical and internal medicine departments were chosen because of the relatively 
IJkema, R., Langelaan, M., Steeg, L. van de, Wagner, C. Do patient characteristics influence nursing adherence to a guideline for preventing delirium? Journal of Nursing Scholarship: 2014, 46(3), 147-156

high percentage of older patients. Twenty hospitals responded within the inclusion period and met the inclusion criterion. Two hospitals withdrew after inclusion due to time constraints and practical issues concerning the trial's intervention. The 18 hospitals remaining included 2 university hospitals, 5 tertiary teaching hospitals, and 11 general hospitals. These hospitals were representative of all hospitals in the Netherlands with regard to size, type, and location.

In each hospital, patient records from both the departments participating were reviewed monthly during an 11-month period (May 2011 until March 2012). The reviewing procedure was performed by trained nurses who were not employed by the hospital during the research period. All nurses were experienced in patient record reviewing. Included in the review were records of patients 70 years of age or older, admitted to the ward or discharged in the preceding week, who had been admitted for at least $24 \mathrm{hr}$ at the moment of the review process. The research nurses selected a random sample of 10 patient records per department (20 per hospital) per month by simple random sampling. This, ideally, would result in 3,960 patient records in total. However, during the study period, each month nurses from one or two participating hospitals gained access to an e-learning course about delirium. To prevent bias in this study, we only included patient records from the period during which no education had taken place yet in the hospitals $(\mathrm{N}=1,881)$.

\section{Process of Reviewing}

Both nursing and medical patient records were reviewed. Data were recorded using a digital questionnaire as a tool to systematically search the entire patient record for information about the following patient characteristics: age, gender, domestic circumstances before admission, comorbidity, dementia, and admission characteristics such as admission department and acute versus a planned admission. In addition, the research nurse registered if and how the patient was screened for delirium, if an increased risk was identified, if the DOSS was used to identify a delirium, and if the DOSS score was high. The study protocol of the trial was approved by the Amsterdam Vrije Universiteit Medical Center Ethics Board. According to Dutch legislation, active informed consent was not required. Nevertheless, in each participating department, posters with information about the study were available. These posters indicated that patients could decline to participate by reporting their withdrawal from the study to the nursing staff.

\section{Outcomes}

Patients were registered as screened if screening had taken place after admission or during a preoperative consultation in the period before hospitalization. Both the three questions recommended from the FEP (see Box 1) and other comparable validated screening tools identifying an increased risk for delirium (e.g., the Groningen Frailty Indicator [GFI; Steverink, Slaets, Schuurmans, \& Van-Lis, 2001]) were eligible for screening. A high risk for delirium was defined as a positive answer on one of the three screening questions advised by the FEP, or a positive score on a validated screening instrument. It has been recorded that the DOSS was used if the observation instrument was applied at least once during admission.

\section{Statistical Analysis}


IJkema, R., Langelaan, M., Steeg, L. van de, Wagner, C. Do patient characteristics influence nursing adherence to a guideline for preventing delirium? Journal of Nursing Scholarship: 2014, 46(3), 147-156

Patient characteristics were analyzed comparing screened and nonscreened patient groups and DOSS use within the group with or without an increased delirium risk (Figure 1). Multilevel logistic regression analysis was performed to take into account the clustering of patients within hospitals and hospital departments. The use of a screening instrument and the application of the DOSS were employed as dependent variables. Gender (male or female), dementia (yes or no), and admission type (acute or planned) were dichotomous independent variables. Categories were created for the independent variable age (70-79 years or $80-89$ years or $\geq 90$ years) and domestic circumstances (living alone, with partner or relative, residential home, nursing home). These were included in the analysis using dummy variables. We also created categories for the independent variable admission department (surgical or internal medicine or other) before adding them as dummy variables into the analysis. We used an adjusted version of the Charlson Comorbidity Index, a weighted comorbidity score based on a 1-year mortality risk, to determine the degree of comorbidity (Hospital Standardized Mortality Ratio, 2012; Sundararajan et al., 2004). Four 1-year mortality risk categories were added as dummies: 0 (none), 1-2 (low), 3-4 (moderate), and $\geq 5$ (high; Charlson, Pompei, Ales, \& MacKenzie, 1987). All data were analyzed using the xtmelogit command in STATA 12.0 (StataCorp LP, Texas, USA).

\section{[FIGURE 1]}

\section{INDINGS}

\section{Quality of Care Delivered}

A total of 1,881 patient records were analyzed. Figure 1 shows a flow chart of the study sample. In $55 \%$ of the patient sample, a risk screening for delirium was conducted, of which $44 \%$ were identified as high-risk patients. The DOSS was used in $48 \%$ of the high-risk group and in $13 \%$ of the patients who were not at risk for delirium, according to screening. Notwithstanding the absence of risk screening, in 130 cases the DOSS was administered.

\section{Patient Characteristics Influencing Adherence}

The screened and nonscreened groups did not differ significantly, except for the variable admission type (Table 2). Patients who were admitted to the hospital as acute cases were less frequently screened compared with those who were planned hospital admissions.

\section{[TABLE 2]}

In the high-risk group, DOSS use was significantly higher in older elderly patients (80-89 years of age) compared to the reference category of patients 70 to 79 years of age (Table 3). Compared with those living alone, patients living in a nursing home before admission were also better represented in the group in which the DOSS was used. On the other hand, living with a partner or relative seemed to reduce the chance that the DOSS was applied, but this difference was not statistically significant. The proportion of patients with dementia, and the percentage of patients admitted to the 
IJkema, R., Langelaan, M., Steeg, L. van de, Wagner, C. Do patient characteristics influence nursing adherence to a guideline for preventing delirium? Journal of Nursing Scholarship: 2014, 46(3), 147-156

hospital as acute cases, was significantly higher in the group in which the DOSS was employed. In the low-risk group, older age was the only factor that influenced whether the DOSS was employed (Table 4). In the nonscreened group, the factors that significantly increased the chance that the DOSS was applied included older age, living in a residential home before admission, a low 1-year mortality risk based on comorbidity, having dementia, and acute admission (Table 5).

\section{[TABLE 3][TABLE 4][TABLE 5]}

\section{DOSS Outcomes}

A high DOSS score was found in 33\% of the patients without a high risk and in 51\% of patients in whom risk screening was not conducted (see Figure 1). The DOSS score was significantly more often high within the high-risk group (53\%) compared to the patient group without an increased risk for delirium (33\%; odds ratio [OR] = 3.62 , confidence interval $[\mathrm{CI}]=1.86-7.05$ ). No statistically significant differences were found between the DOSS outcome in the nonscreened versus the screened patient groups $(\mathrm{OR}=0.73, \mathrm{CI}=0.44-1.20)$. Neither were any differences found when comparing DOSS outcomes in the nonscreened group with those in the screened high-risk group $(\mathrm{OR}=1.00, \mathrm{CI}=0.59-1.71)$.

\section{DISCUSSION}

The implementation and use of clinical practice guidelines among nurses is a complex process in which social and organizational barriers concerning workload, communication, and education play an important role (Abrahamson, Fox, \& Doebbeling, 2012). In this light, a moderate adherence to a complex multicomponent delirium prevention program, as our results show, is perhaps not surprising. In acute situations (e.g., solving life-threatening problems), nurses may have priorities other than risk screening. Previous research in trauma patients has shown that these patients receive less than two thirds of the care recommended by evidence-based medicine (Rayan et al., 2012). And the fact that patients are often initially admitted to another department other than that to which they are to spend the rest of their stay in the hospital may make it unclear which department is responsible for risk screening. Furthermore, the FEP's recommendations are compiled on the basis of existing literature about preventing delirium, but the effectiveness of the FEP's screening questions is not scientifically proven. This might have influenced adherence, since previous studies among physicians have shown that their willingness to adopt guidelines largely depends on the degree of scientific basis for the guidelines (Goossens, Bossuyt, \& de Haan, 2008; Hader et al., 2007). Significantly, not only the results of screening, but also the characteristics of the patient, determine whether the DOSS is used. The DOSS is also applied in some cases in which no risk screening was employed, and in some cases within the group in which no high risk was identified. This indicates that patient characteristics influence DOSS use in screened as well as in nonscreened patients. It is especially true that in the highest age group and in patients with dementia, the DOSS is often applied in spite of a lack of a high risk or even a risk screening. This may be 
IJkema, R., Langelaan, M., Steeg, L. van de, Wagner, C. Do patient characteristics influence nursing adherence to a guideline for preventing delirium? Journal of Nursing Scholarship: 2014, 46(3), 147-156

explained by the fact that these groups are often confused for other reasons, which may lead staff to believe that a delirium has occurred.

DOSS outcomes show that nurses were often right in their decision to start using the DOSS in the patient group without a high risk based on risk screening, because 33\% of these patients were identified as probably delirious anyway. This result supports the view that it is not sufficient to simply follow the professional guideline strictly. It may even pose a threat. Harm such as misclassification, resulting in withholding patients from potentially beneficial treatment or leading to unnecessary treatment, could occur (Greer et al., 2011).

Future research should elaborate further on the specificity and sensitivity of the professional guideline. How many people are wrongly classified and what are the consequences? Furthermore, DOSS outcomes do not differ significantly between screened and nonscreened patients. Therefore, more research is needed to determine the effect of prevention programs such as the FEP on the incidence of delirium. It should be noted that this study has some methodological limitations. Firstly, a disadvantage of the method of record reviewing used in this study is that there might be a difference between the care provided, as registered in the patient record, and the care actually delivered to the patient. In other words, the quality of patient records might have influenced our study outcomes. A previous study that examined quality of patient record keeping indicated that nursing and medical records were often inadequate. It concluded that better registration would benefit the quality of care (Zegers et al., 2011). Secondly, the interpretation of the research questionnaire, as well as patient records, could have varied between research nurses. However, we minimized any potential interpretation bias by giving oral and written instructions and keeping a frequently asked questions (FAQ) list. Thirdly, the FEP recommends DOSS use during three successive shifts. In our study, we determined the percentage of patients in which the DOSS was used at least once, given the very low number of patients in which the DOSS is actually used three times. This is in line with the indicator of the Dutch Health Care Inspectorate (2011), but as a practical consequence, it can be assumed that some patients are classified incorrectly as nondelirious. Lastly, we used a very broad definition of screening. This applied both to the FEP questions as well as other screening instruments to identify a risk of delirium. Consequently, we did not take into account the fact that one instrument might be better than the other, although there are no indications in the literature which show that.

\section{CONCLUSIONS}

Patient characteristics do influence nursing delirium care, together with the instructions supplied with the professional guideline. Although they do not influence delirium risk screening, patient characteristics largely influence DOSS use. We recommend that more research is needed on the effect of the guideline on the incidence of delirium in order to determine whether deviating from the guideline by taking patient characteristics into account has implications for improving the prevention of delirium.

\section{Acknowledgments}


IJkema, R., Langelaan, M., Steeg, L. van de, Wagner, C. Do patient characteristics influence nursing adherence to a guideline for preventing delirium? Journal of Nursing Scholarship: 2014, 46(3), 147-156

This study is part of a larger study investigating the implementation of a quality improvement program for older patients funded by the Dutch Ministry of Health, Welfare and Sport.

\section{Clinical Resource}

Dutch Patient Safety Program: http://www.vmszorg.nl

\section{REFERENCES}

Abrahamson, K. A., Fox, R. L., \& Doebbeling, B. N. (2012). Facilitators and barriers to clinical practice guideline use among nurses. American Journal of Nursing, 112, 26-35.

Boorsma, M., Joling, K. J., Frijters, D. H., Ribbe, M. E., Nijpels, G., \& van Hout, H. P. (2012). The prevalence, incidence and risk factors for delirium in Dutch nursing homes and residential care homes. International Journal of Geriatric Psychiatry, 27, 709-715.

Charlson, M. E., Pompei, P., Ales, K. L., \& MacKenzie, C. R. (1987). A new method of classifying prognostic comorbidity in longitudinal studies: Development and validation. Journal of Chronic Diseases, 40, 373-383.

Dutch Health Care Inspectorate. (2011). Basisset Kwaliteitsindicatoren ziekenhuizen 2012 (in Dutch). Utrecht, the Netherlands: Author.

Dutch Health Care Inspectorate. (2013). The results count hospitals 2011 (in Dutch). Utrecht, the Netherlands: Author.

Dutch Patient Safety Program. (2012). Kwetsbare ouderen. Retrieved from http://www.vmszorg.nl/_library/5540/web_2009.0104_praktijkgids_kwetsbare_ouderen.pdf

Eeles, E. M., Hubbard, R. E., White, S. V., O'Mahony, M. S., Savva, G. M., \& Bayer, A. J. (2010). Hospital use, institutionalisation and mortality associated with delirium. Age and Ageing, 39, 470-475.

Elie, M., Cole, M. G., Primeau, F. J., \& Bellavance, F. (1998). Delirium risk factors in elderly hospitalized patients. Journal of General Internal Medicine, 13, 204-212.

Goossens, A., Bossuyt, P. M., \& de Haan, R. J. (2008). Physicians and nurses focus on different aspects of guidelines when deciding whether to adopt them: An application of conjoint analysis. Medical Decision Making, 28, 138-145.

Greer, N., Rossom, R., Anderson, P., MacDonald, R., Tacklind, J., Rutks, I., \& Wilt, T. J. (2011). Delirium: Screening, prevention, and diagnosis-a systematic review of the evidence. VA-ESP Project \#09-009. Minneapolis, MN: Evidence-based Synthesis Program (ESP) Center.

Hader, J. M., White, R., Lewis, S., Foreman, J. L., McDonald, P. W., \& Thompson, L. G. (2007). Doctors' views of clinical practice guidelines: A qualitative exploration using innovation theory. Journal of Evaluation in Clinical Practice, 13, 601-606.

Hospital Standardized Mortality Ratio. (2012). Charlson index voor comorbiditeit. Retrieved from http://www.hsmr.nl/index.php?option=com_content\&view=article\&id=53

Inouye, S. K. (2006). Delirium in older persons. New England Journal of Medicine, 354, $1157-1165$

Inouye, S. K., Bogardus, S. T., Jr, Charpentier, P. A., Leo-Summers, L., Acampora, D., Holford, T. R., \& Cooney, L. M. Jr. (1999). A multicomponent intervention to prevent delirium in hospitalized older patients. New England Journal of Medicine, 340, 669-676.

Inouye, S. K., Viscoli, C. M., Horwitz, R. I., Hurst, L. D., \& Tinetti, M. E. (1993). A predictive model for delirium in hospitalized elderly medical patients based on admission characteristics. Annals of Internal Medicine, 119, 474-481.

Inouye, S. K., Zhang, Y., Jones, R. N., Kiely, D. K., Yang, F., \& Marcantonio, E. R. (2007). Risk factors for delirium at discharge: Development and validation of a predictive model. Archives of Internal Medicine, 167, 1406-1413.

Kalisvaart, K. J., Vreeswijk, R., de Jonghe, J. F., van der Ploeg, T., van Gool, W. A., \& Eikelenboom, P. (2006). Risk factors and prediction of postoperative delirium in elderly hip- 
IJkema, R., Langelaan, M., Steeg, L. van de, Wagner, C. Do patient characteristics influence nursing adherence to a guideline for preventing delirium? Journal of Nursing Scholarship: 2014, 46(3), 147-156

surgery patients: Implementation and validation of a medical risk factor model. Journal of the American Geriatric Society, 54, 817-822.

Leslie, D. L., Marcantonio, E. R., Zhang, Y., Leo-Summers, L., \& Inouye, S. K. (2008). Oneyear health care costs associated with delirium in the elderly population. Archives of Internal Medicine, 168, 27-32.

Milisen, K., Lemiengre, J., Braes, T., \& Foreman, M. D. (2005). Multicomponent intervention strategies for managing delirium in hospitalized older people: Systematic review. Journal of Advanced Nursing, 52, 79-90.

Rahkonen, T., Eloniemi-Sulkava, U., Halonen, P., Verkkoniemi, A., Niinistö, L., Notkola, I. L., \& Sulkava, R. (2001). Delirium in the non-demented oldest old in the general population: Risk factors and prognosis. International Journal of Geriatric Psychiatry, 16, 415-421.

Rayan, N., Barnes, S., Fleming, N., Kudyakov, R., Ballard, D., Gentilello, L. M., et al. (2012). Barriers to compliance with evidence-based care in trauma. Journal of Trauma and Acute Care Surgery, 72, 585-592.

Schuurmans, M. J. (2001). Early recognition of delirium. Utrecht, the Netherlands: Utrecht University.

Schuurmans, M. J., Deschamps, P. I., Markham, S. W., Shortridge-Baggett, L. M., \& Duursma, S. A. (2003). The measurement of delirium: Review of scales. Research and Theory for Nursing Practice, 17, 207-224.

Schuurmans, M. J., Shortridge-Baggett, L. M., \& Duursma, S. A. (2003). The Delirium Observation Screening Scale: A screening instrument for delirium. Research and Theory for Nursing Practice, 17, 31-50.

Siddiqi, N., House, A. O., \& Holmes, J. D. (2006). Occurrence and outcome of delirium in medical in-patients: A systematic literature review. Age and Ageing, 35, 350-364.

Steverink, N., Slaets, J. P. J., Schuurmans, H., \& Van-Lis, M. (2001). Measuring frailty. Development and testing of the Groningen Frailty Indicator (GFI). Gerontologist, 41, 236237.

Sundararajan, V., Henderson, T., Perry, C., Muggivan, A., Quan, H., \& Ghali, W. A. (2004). New ICD-10 version of the Charlson comorbidity index predicted in-hospital mortality. Journal of Clinical Epidemiology, 57, 1288-1294.

Van de Steeg, L., Langelaan, M., ljkema, R., \& Wagner, C. (2012). The effect of a complementary e-learning course on implementation of a quality improvement project regarding care for elderly patients: A stepped wedge trial. Implementation Science, 7(13), 13. doi: $10.1186 / 1748-5908-7-13$

van Gemert, L. A., \& Schuurmans, M. J. (2007). The Neecham Confusion Scale and the Delirium Observation Screening Scale: Capacity to discriminate and ease of use in clinical practice. BMC Nursing, 6(3), 3.

VMS Veiligheidsprogramma. (2012). Over het VMS veiligheidsprogramma [Dutch patient safety program]. Retrieved from http://www.vmszorg.nl/over-ons

Zegers, M., de Bruijne, M. C., Spreeuwenberg, P., Wagner, C., Groenewegen, P. P., \& van der Wal, G. (2011). Quality of patient record keeping: An indicator of the quality of care? BMJ Quality \& Safety, 20, 314-318.

Zhang, H., Lu, Y., Liu, M., Zou, Z., Wang, L., Xu, F. Y., \& Shi, X. Y. (2013). Strategies for prevention of postoperative delirium: A systematic review and meta-analysis of randomized trials. Critical Care, 17(2). Retrieved from http://ccforum.com/content/17/2/R47 
IJkema, R., Langelaan, M., Steeg, L. van de, Wagner, C. Do patient characteristics influence nursing adherence to a guideline for preventing delirium? Journal of Nursing Scholarship: 2014, 46(3), 147-156

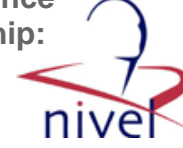

\section{TABLES}

Table 1. Recommended Screening Questions According to Frail Elderly Project Guide (www.vmszorg.nl)

1. Do you experience memory problems?

2. Have you needed help with self-care in the past $24 \mathrm{hr}$ ?

3. Have you experienced periods of confusion during earlier hospital stays or illness?

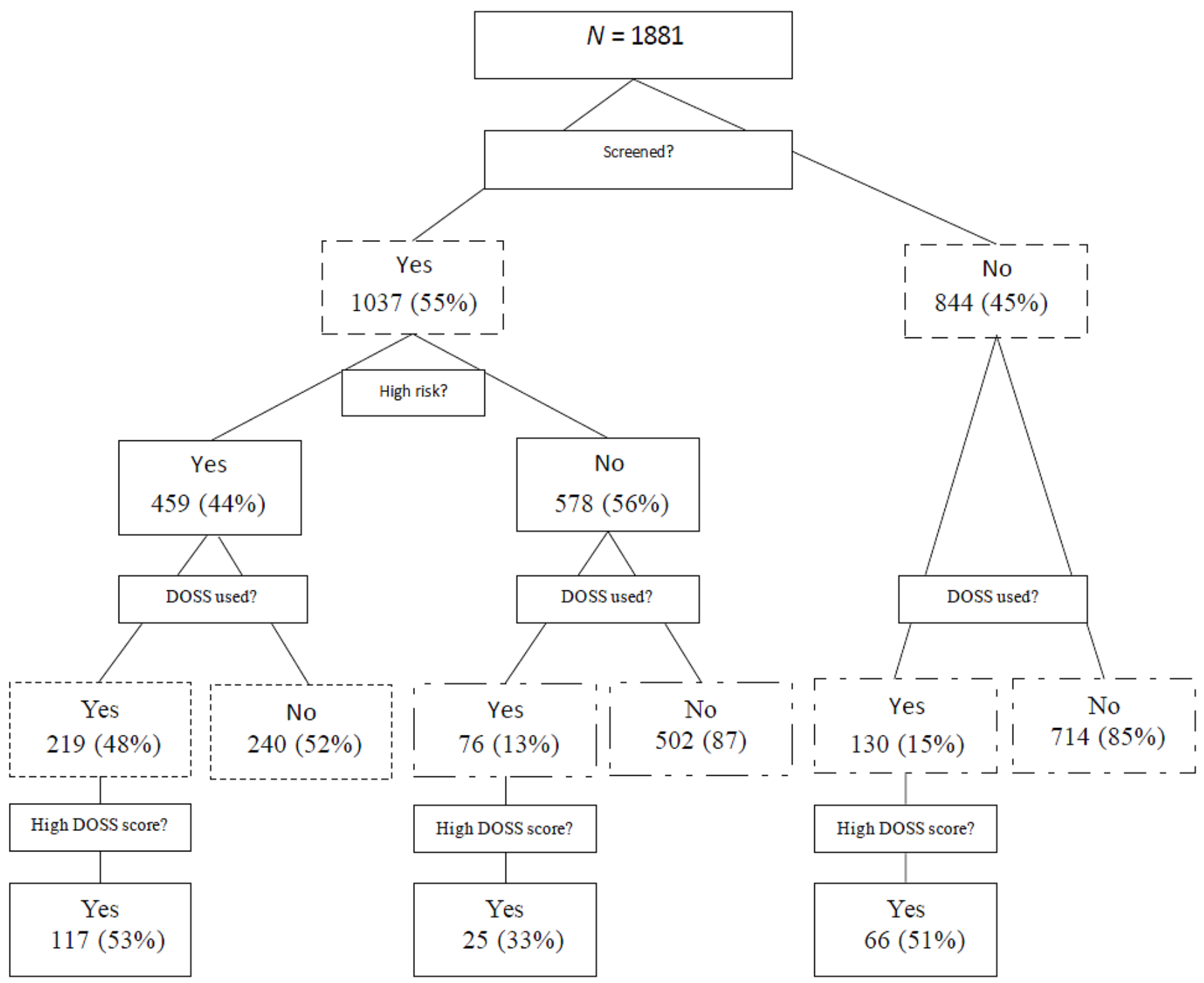

Figure 1. Flow chart of the study sample. The dashed lines indicate the groups that are compared in Table $1(---)$, Table $2(\cdots \cdots)$, Table $3(-. \cdot)$, and Table $4(-\cdot-)$. 
IJkema, R., Langelaan, M., Steeg, L. van de, Wagner, C. Do patient characteristics influence nursing adherence to a guideline for preventing delirium? Journal of Nursing Scholarship: 2014, 46(3), 147-156

Table 2. Patient Characteristics Influencing Risk Screening $(N=1,881)$

\begin{tabular}{|c|c|c|c|c|}
\hline Variable & $\begin{array}{c}\text { Screened population } \\
\begin{array}{c}n=1,037 \\
n(\%)\end{array}\end{array}$ & $\begin{array}{l}\text { Nonscreened population } \\
\qquad \begin{array}{c}n=844 \\
n(\%)\end{array}\end{array}$ & Odds ratio & $95 \%$ confidence interval \\
\hline $70-79$ & $423(40.8)$ & $340(40.3)$ & $\mathrm{rc}$ & \\
\hline $80-89$ & $489(47.2)$ & $416(49.3)$ & 1.04 & $0.82-1.32$ \\
\hline$\geq 90$ & $125(12.0)$ & $88(10.4)$ & 1.10 & $0.76-1.60$ \\
\hline Female & $571(55.1)$ & $473(56.0)$ & $\mathrm{rc}$ & \\
\hline Male & $466(44.9)$ & $371(44.0)$ & 0.96 & $0.77-1.20$ \\
\hline Domestic circumstances & $(n=1,025)$ & $(n=785)$ & & \\
\hline Living alone & $353(34.4)$ & $299(38.1)$ & $\mathrm{rc}$ & \\
\hline Living with partner/relative & $456(44.5)$ & $343(43.7)$ & 0.94 & $0.73-1.22$ \\
\hline Residential home & $166(16.2)$ & $98(12.5)$ & 1.42 & $0.98-2.06$ \\
\hline $1-2$ (low) & $453(43.7)$ & $385(45.6)$ & 1.04 & $0.78-1.38$ \\
\hline 3-4 (moderate) & $174(16.8)$ & $162(19.2)$ & 0.95 & $0.67-1.36$ \\
\hline$\geq 5$ (high) & $124(11.9)$ & $88(10.4)$ & 1.21 & $0.80-1.84$ \\
\hline \multicolumn{5}{|l|}{ Dementia } \\
\hline Nondemented & $968(93.4)$ & $811(96.1)$ & $\mathrm{rc}$ & \\
\hline Demented & $69(6.6)$ & $33(3.9)$ & 1.53 & $0.91-2.56$ \\
\hline \multicolumn{5}{|l|}{ Admission type } \\
\hline Planned & $329(31.7)$ & $213(25.2)$ & $\mathrm{rc}$ & \\
\hline Acute & $708(68.3)$ & $631(74.8)$ & 0.64 & $0.48-0.84$ \\
\hline \multicolumn{5}{|l|}{ Admission department } \\
\hline Internal medicine ward & $518(49.9)$ & $415(49.2)$ & $\mathrm{rc}$ & \\
\hline
\end{tabular}

Note. $\mathrm{rc}=$ reference category. Boldface values indicate that the variable shows significance.

${ }^{a}$ Charlson Comorbidity Index: a weighted sum score, based on the relative risk of 1-year mortality for each of 17 comorbidities, was used to predict mortality (Sundararajan et al., 2004). 
IJkema, R., Langelaan, M., Steeg, L. van de, Wagner, C. Do patient characteristics influence nursing adherence to a guideline for preventing delirium? Journal of Nursing Scholarship: 2014, 46(3), 147-156

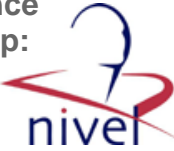

Table 3. Patient Characteristics Influencing Delirium Observation Screening Scale (DOSS) Use Within the Population With a High Risk ( $N=459$ )

\begin{tabular}{|c|c|c|c|c|}
\hline Variable & $\begin{array}{c}\text { DOSS used } \\
n=219 \\
n(\%)\end{array}$ & $\begin{array}{c}\text { DOSS not used } \\
n=240 \\
n(\%)\end{array}$ & Odds ratio & $95 \%$ confidence interval \\
\hline \multicolumn{5}{|l|}{ Age (years) } \\
\hline $70-79$ & $49(22.4)$ & $68(28.3)$ & $\mathrm{rc}$ & \\
\hline $80-89$ & $133(60.7)$ & $124(51.7)$ & 1.72 & $1.05-2.81$ \\
\hline$\geq 90$ & $37(16.9)$ & $48(20.0)$ & 1.41 & $0.75-2.66$ \\
\hline \multicolumn{5}{|l|}{ Gender } \\
\hline Female & $118(53.9)$ & $143(59.6)$ & $\mathrm{rc}$ & \\
\hline Male & $101(46.1)$ & $97(40.4)$ & 1.28 & $0.85-1.94$ \\
\hline Domestic circumstances & $(n=217)$ & $(n=234)$ & & \\
\hline Living alone & $68(31.3)$ & $73(31.2)$ & $\mathrm{rc}$ & \\
\hline Living with partner/relative & $60(27.6)$ & $78(33.3)$ & 0.71 & $0.42-1.20$ \\
\hline Residential home & $57(26.3)$ & $69(29.5)$ & 1.10 & $0.63-1.89$ \\
\hline Nursing home & $32(14.8)$ & $14(6.0)$ & 2.46 & $1.10-5.50$ \\
\hline \multicolumn{5}{|l|}{ Charlson index * } \\
\hline 0 (none) & $38(17.3)$ & $50(20.8)$ & $\mathrm{rc}$ & \\
\hline $1-2$ (low) & $105(48.0)$ & $107(44.6)$ & 1.00 & $0.56-1.79$ \\
\hline 3-4 (moderate) & $41(18.7)$ & $51(21.3)$ & 0.71 & $0.36-1.44$ \\
\hline$\geq 5$ (high) & $35(16.0)$ & $32(13.3)$ & 1.05 & $0.49-2.23$ \\
\hline \multicolumn{5}{|l|}{ Dementia } \\
\hline Nondemented & $177(80.8)$ & $218(90.8)$ & $\mathrm{rc}$ & \\
\hline Demented & $42(19.2)$ & $22(9.2)$ & 2.58 & $1.39-4.78$ \\
\hline \multicolumn{5}{|l|}{ Admission type } \\
\hline Planned & $34(15.5)$ & $55(22.9)$ & $\mathrm{rc}$ & \\
\hline Acute & $185(84.5)$ & $185(77.1)$ & 2.12 & $1.21-3.71$ \\
\hline \multicolumn{5}{|l|}{ Admission department } \\
\hline Internal medicine ward & $123(56.2)$ & $129(53.8)$ & $\mathrm{rc}$ & \\
\hline Surgical ward & $95(43.4)$ & $109(45.4)$ & 0.95 & $0.62-1.46$ \\
\hline Other & $1(0.46)$ & $2(0.8)$ & 0.32 & $0.03-3.86$ \\
\hline
\end{tabular}

Note. $\mathrm{rc}=$ reference category. Boldface values indicate that the variable shows significance.

${ }^{a}$ Charlson Comorbidity Index: a weighted sum score, based on the relative risk of 1-year mortality for each of 17 comorbidities, was used to predict mortality (Sundararajan et al., 2004). 
IJkema, R., Langelaan, M., Steeg, L. van de, Wagner, C. Do patient characteristics influence nursing adherence to a guideline for preventing delirium? Journal of Nursing Scholarship: 2014, 46(3), 147-156

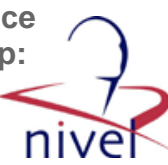

Table 4. Patient Characteristics Influencing Delirium Observation Screening Scale (DOSS) Use Within the Screened Population Without a High Risk ( $N=$ 578)

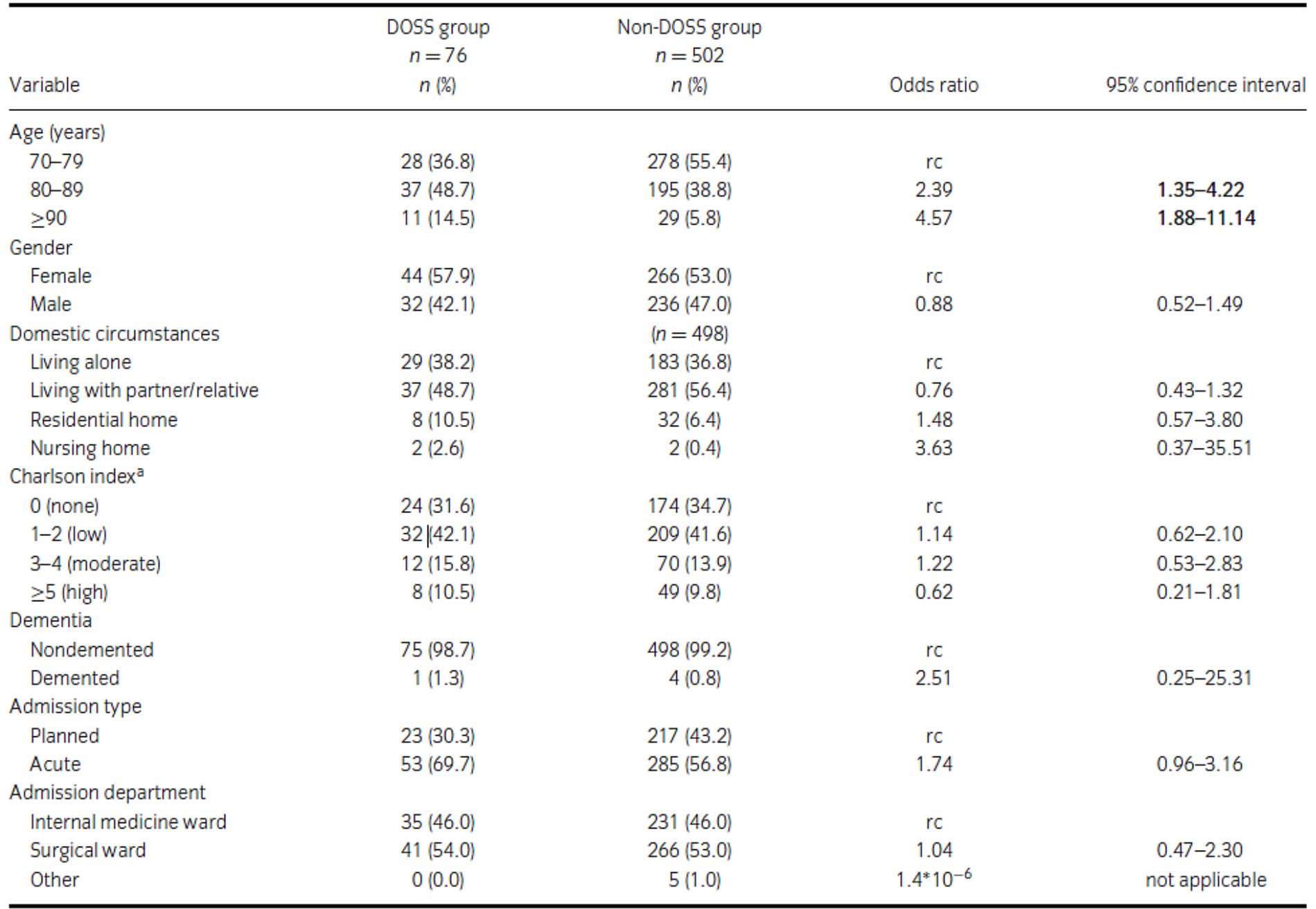

Note. $\mathrm{rc}=$ reference category. Boldface values indicate that the variable shows significance.

${ }^{a}$ Charlson Comorbidity Index: a weighted sum score, based on the relative risk of 1-year mortality for each of 17 comorbidities, was used to predict mortality (Sundararajan et al., 2004). 
IJkema, R., Langelaan, M., Steeg, L. van de, Wagner, C. Do patient characteristics influence nursing adherence to a guideline for preventing delirium? Journal of Nursing Scholarship: 2014, 46(3), 147-156

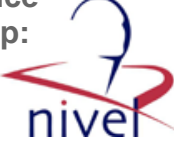

Table 5. Patient Characteristics Influencing Delirium Observation Screening Scale (DOSS) Use Within the Nonscreened Population ( $N=844$ )

\begin{tabular}{|c|c|c|c|c|}
\hline Variable & $\begin{array}{c}\text { DOSS group } \\
n=130 \\
n(\%)\end{array}$ & $\begin{array}{c}\text { Non-DOSS group } \\
n=714 \\
n(\%)\end{array}$ & Odds ratio & $95 \%$ confidence interval \\
\hline 70-79 & $33(25.4)$ & $307(43.0)$ & $\mathrm{rc}$ & \\
\hline $80-89$ & $71(54.6)$ & $345(48.3)$ & 2.10 & $1.33-3.32$ \\
\hline$\geq 90$ & $26(20.0)$ & $62(8.7)$ & 4.36 & $2.32-8.19$ \\
\hline Female & $77(59.2)$ & $396(55.5)$ & $\mathrm{rc}$ & \\
\hline Male & $53(40.8)$ & $318(44.5)$ & 0.83 & $0.56-1.23$ \\
\hline Domestic circumstances & $(n=125)$ & $(n=660)$ & & \\
\hline Living alone & $49(39.2)$ & $250(37.9)$ & $\mathrm{rc}$ & \\
\hline Living with partner/relative & $46(36.8)$ & $297(45.0)$ & 0.79 & $0.50-1.25$ \\
\hline Residential home & $23(18.4)$ & $75(11.3)$ & 1.98 & $1.07-3.66$ \\
\hline $1-2$ (low) & $76(58.5)$ & $309(43.3)$ & 1.98 & $1.16-3.34$ \\
\hline 3-4 (moderate) & $21(16.2)$ & $141(19.7)$ & 1.16 & $0.59-2.26$ \\
\hline$\geq 5$ (high) & $9(6.9)$ & $79(11.1)$ & 0.79 & $0.33-1.91$ \\
\hline \multicolumn{5}{|l|}{ Dementia } \\
\hline Nondemented & $118(90.8)$ & $693(97.1)$ & $\mathrm{rc}$ & \\
\hline Demented & $12(9.2)$ & $21(2.9)$ & 5.03 & $2.26-11.20$ \\
\hline \multicolumn{5}{|l|}{ Admission type } \\
\hline Planned & $20(15.4)$ & $193(27.0)$ & $\mathrm{rc}$ & \\
\hline Acute & $110(84.6)$ & $521(73.0)$ & 2.02 & $1.18-3.46$ \\
\hline \multicolumn{5}{|l|}{ Admission department } \\
\hline Internal medicine ward & $70(53.9)$ & $345(48.3)$ & $\mathrm{rc}$ & \\
\hline
\end{tabular}

Note. $\mathrm{rc}=$ reference category. Boldface values indicate that the variable shows significance.

${ }^{a}$ Charlson Comorbidity Index: a weighted sum score, based on the relative risk of 1-year mortality for each of 17 comorbidities, was used to predict mortality (Sundararajan et al., 2004). 